\title{
Sensory marketing, embodiment, and grounded cognition: A review and introduction
}

\author{
Aradhna Krishna ${ }^{a}$, Norbert Schwarz ${ }^{\text {b,c,* }}$ \\ ${ }^{a}$ Ross School of Business, University of Michigan, Ann Arbor, USA \\ ${ }^{\mathrm{b}}$ Department of Psychology, University of Southern California, Los Angeles, USA \\ ${ }^{\mathrm{c}}$ Marshall School of Business, University of Southern California, Los Angeles, USA
}

Received 22 December 2013; accepted 23 December 2014

Available online 24 December 2013

\begin{abstract}
There has been a recent swell of interest in marketing as well as psychology pertaining to the role of sensory experiences in judgment and decision making. Within marketing, the field of sensory marketing has developed which explores the role of the senses in consumer behavior. In psychology, the dominant computer metaphor of information processing has been challenged by researchers demonstrating various manners in which mental activity is grounded in sensory experience. These findings are arduous to explain using the amodal model of the human mind. In this introduction, we first delineate key assumptions of the information processing paradigm and then discuss some of the key conceptual challenges posed by the research generally appearing under the titles of embodiment, grounded cognition, or sensory marketing. We then address the use of bodily feelings as a source of information; next, we turn to the role of context sensitive perception, imagery, and simulation in consumer behavior, and finally discuss the role of metaphors. Through this discourse, we note the contributions to the present special issue as applicable.
\end{abstract}

(C) 2013 Society for Consumer Psychology. Published by Elsevier Inc. All rights reserved.

\section{Introduction}

In recent years, the role of sensory experiences in judgment and decision making has seen a surge of interest in marketing as well as psychology. In marketing, scattered research on the role of the senses in consumer behavior has been brought together under the rubric of sensory marketing, that is, "marketing that engages the consumers' senses and affects their perception, judgment, and behavior" (Krishna, 2012, p. 332; for reviews, see Krishna, 2012, 2013, and the contributions in Krishna, 2010). In psychology, researchers challenged the dominant computer metaphor of information processing by highlighting ways in which mental activity is grounded in sensory experience (for reviews, see Barsalou, 2008; Meier, Schnall, Schwarz, \& Bargh, 2012; Niedenthal, Barsalou, Winkielman, Krauth-Gruber, $\&$ Ric, 2005). The rapidly accumulating empirical findings are

\footnotetext{
* Corresponding author at: Dept of Psychology, University of Southern California, 3620 S. McClintock Ave, Los Angeles, CA 90089-1061, USA. E-mail address: norbert.schwarz@usc.edu (N. Schwarz).
}

often surprising and difficult to account for within the amodal model of the human mind that has dominated psychology and consumer research since the cognitive revolution of the 1970s. The findings also amplify earlier challenges to models of rational choice - anybody who was dismayed by the observation that different ways of presenting a choice alternative can affect choice (for reviews, see the contributions in Lichtenstein \& Slovic, 2006) will be even more dismayed by the extent to which incidental exposure to sensory experiences in one domain can affect choice in another, substantively unrelated domain (for a review, see Lee \& Schwarz, 2014).

As the history of science illustrates, at early stages of a research program the focus is often on identifying challenges to dominant paradigms in the hope that they will capture a field's attention (Root-Bernstein, 1989). At that stage, documenting novel phenomena that are difficult to account for by the dominant paradigm takes precedence over understanding the details of how the new phenomena operate. Consistent with this regularity, early "embodiment" experiments focused on highlighting findings that one would not expect on the basis of traditional models of 
judgment and decision making, whereas distinctions between different theoretical approaches to embodiment received less attention (for an early discussion, see Anderson, 2008). More recently, researchers began testing competing theories of the underlying processes; history suggests that this will be the focus of future research in this area. At present, however, there is wide consensus that we cannot understand human cognition without taking into account that humans interact with the world through their senses and do their thinking within a body; but there is much less consensus about what this implies and how it is best conceptualized. Moreover, the different emerging theoretical perspectives are not necessarily mutually exclusive and different processes may contribute to observed effects under different conditions.

Our introduction to this special issue of the Journal of Consumer Psychology summarizes these developments, notes different theoretical perspectives, and places the contributions to the special issue in their context. We begin by revisiting key assumptions of the information processing paradigm that has dominated consumer psychology for the last four decades and note some of the conceptual challenges posed by recent research commonly presented under the headings of embodiment, grounded cognition, or sensory marketing. As this research moves beyond initial attention-grabbing illustrations, researchers are increasingly identifying limiting conditions and competing pathways, a step that is central to understanding the phenomena and the conditions under which they can (or cannot) be reliably replicated. While the often counterintuitive and amusing nature of some of the iconic findings adds to their popular interest value, it also distracts casual observers (and reviewers) from the fact that the findings pose serious challenges to how we think about the human mind. Next, we note these conceptual challenges.

\section{Information processing, with and without a body: a historical perspective}

In the 1970s, the development of general models of information processing provided an integrative framework for the conceptualization of human memory, judgment, and decision making (for authoritative contemporary treatments, see Lachman, Lachman, \& Butterfield, 1979; Wyer, 1974). In a nutshell, the approach assumed that people acquire information through their senses and that this information is translated into a common code that is independent of the modality in which the information was initially acquired. These amodal representations were assumed to be the building blocks of knowledge (semantic memory), on which the mind operates with general procedures that are also independent of the initial modality. Once stored, knowledge representations were assumed to be context independent, although context could influence how easily a stored representation could be accessed. These assumptions were consistent with a computer metaphor that emphasized encoding, storage, and retrieval operations and took it for granted that all operations require a common format, paralleling the operational requirements of a computer. Their emphasis on amodal knowledge representation was a sharp break with centuries of earlier theorizing that took it for granted that visual, olfactory or haptic inputs were stored in a form that reflected the modality of their acquisition. In fact, having a controversial discussion about whether imagery involves anything like an image (e.g., Paivio, 1971; Pylyshyn, 1973) would have been unimagineable prior to the information processing paradigm (and the controversy has been settled in favor of modal representations; see Kosslyn, Thompson, \& Ganis, 2006).

While the information processing paradigm facilitated enormous progress in psychological research, it also came with its own blind spots (for a discussion, see Schwarz, 2000). Most notably, it neglected phenomena that were not easily conceptualized within a computer metaphor, including the role of moods, emotions, and other subjective experiences as well as the role of motivation, which was reduced to processing goals. Given their subject matter, these limitations were particularly apparent to social psychologists, who integrated the role of feelings and "hot" motivational processes in the social cognition variants of information processing models, paying tribute to social psychology's long tradition of attending to visceral aspects of social perception and behavior (for reviews, see Schwarz \& Clore, 2007; Strack \& Deutsch, 2007). For the most part, however, social cognition theories did not fundamentally challenge the assumption of amodal representations. Instead, feelings and bodily states were themselves assumed to be stored in memory in an amodal form, for example, as nodes in a semantic network (e.g., Bower, 1981), although they provided "online" information that competed with the amodally represented "offline" information stored in memory (e.g., Schwarz, 1990). Some current embodiment research is compatible with this tradition and addresses how concurrent bodily experiences serve as a source of information in judgment and choice; these processes can be conceptualized within feelings-as-information theory (Schwarz, 2012) and we address this work in the section on bodily feelings as information.

Going beyond these extensions of the information processing paradigm, the assumption of a largely decontextualized and amodal mind has been questioned more radically by several streams of research that converge in support of an emerging metatheoretical narrative that emphasizes the situated, experiential, and embodied nature of human cognition. Following early insights of William James (1890), situated cognition research assumes that thinking is for doing and that any mind worth having needs to be geared towards facilitating action in ways that are sensitive to the requirement of one's current situation (for a review, see Smith \& Semin, 2004). This perspective turns contextual influences on judgment and choice from deplorable "context dependency" into laudable "context sensitivity", with far reaching consequences for the conceptualization of preferences, attitudes, and related concepts (for a discussion, see Schwarz, 2007). Because people experience the world through their senses, sensory information and the accompanying subjective experiences play a key role in human action and cognition, even in domains that seem abstract and far removed from immediate sensory inputs. Some suggest that this reflects that humans "evolved from creatures whose neural resources were devoted 
primarily to perceptual and motoric processing" (Wilson, 2002, p. 625). The later development of higher mental processes presumably took advantage of these evolutionarily older programs and reused them for new purposes (Anderson, 2010). From this perspective, what psychologists traditionally referred to as "higher mental processes" is grounded in bodily experience because it reuses phylogenetically older neural circuitry (for a review of supporting evidence, see Anderson, 2010). Others emphasize ontogenetic rather than phylogenetic learning and suggest that early sensory experience with the physical and social world (e.g., feeling warm and safe in the presence of a caregiver) structures later thinking about abstract concepts (e.g., security), resulting in associations between sensory experience and abstract thought across content domains (e.g., Williams, Huang, \& Bargh, 2009).

Independent of specific assumptions about their origin, links between sensory experience and abstract concepts are often reflected in widely shared metaphors (for a review, see Landau, Meier, \& Keefer, 2010). For example, a relationship may be described as "cold" or "warm" — and, indeed, experiencing physical warmth through touching a warm object increases the perception of social warmth in others (e.g., Williams \& Bargh, 2008), much as the social experience of a "cold shoulder" influences perceptions of the physical temperature of the room (e.g., Zhong \& Leonardelli, 2008). A large part of current embodiment research in consumer psychology addresses such metaphorical influences; we discuss key findings and conceptual controversies in the section on metaphors.

Finally, the most radical approach to grounded cognition conceptualizes all mental acts as acts of modality specific sensory simulation (e.g., Barsalou, 1999; Barsalou, Niedenthal, Barbey, \& Ruppert, 2003). From this perspective, "as an experience occurs (e.g., easing into a chair), the brain captures states across the modalities and integrates them with a multimodal representation stored in memory (e.g., how a chair looks and feels, the action of sitting, introspections of comfort and relaxation)" (Barsalou, 2008, p. 618). Such multimodal representations can be activated through any of the participating modalities. More important, thinking about a chair is assumed to involve a simulation of previous sensory experience, making simulations of earlier experience an essential part of any mental activity. Supporting this rationale, a large body of neuroimaging findings shows that supposedly amodal "high level" processes - such as language comprehension, categorization, or retrieval - entail activation of the brain areas involved in "low level" sensory processing (for a review, see Barsalou, 2008). This approach is increasingly informing research in sensory marketing that explores the role of mental simulation in advertising and related issues (e.g., Elder \& Krishna, 2012), as reviewed below.

The next three sections elaborate on these core themes. We first address the use of bodily feelings as a source of information, which is most compatible with traditional social cognition models; next, we turn to the role of context sensitive perception, imagery, and simulation in consumer behavior, and finally discuss the role of metaphors. Throughout, we note the contributions to the present special issue as applicable.

\section{Bodily experience as a source of information}

The assumption that people attend to their own bodily states and extract information from them has a long tradition in art, philosophy, and psychology. From the heart that beats faster when seeing the loved one to the cold sweat of fear, perceptions of bodily states figure prominently in poems, songs, and popular images. Experimental studies confirm that bodily states inform human judgment and that people use this information as they use any other information (for reviews, see Herbert \& Pollatos, 2012; Schwarz \& Clore, 2007). Consistent with the logic of feelings-as-information theory (for a recent review, see Schwarz, 2012), the impact of bodily states depends on their perceived informational value; it is attenuated or eliminated when the experience is attributed to an unrelated source, and enhanced when it is experienced despite contrary influences. A fast beating heart indeed increases the attractiveness of pin-up photos, unless one realizes that the elevated heart beat may be the result of having climbed several flights of stairs (Zillman, 1978). Similarly, physiological symptoms of fear increase the impact of a fear-arousing movie, in particular when they are experienced despite having taken an allegedly tranquilizing pill; yet their influence is eliminated when the symptoms can be attributed to an allegedly arousing pill (Schwarz, Servay, \& Kumpf, 1985).

Facilitating or impairing a person's bodily response to a stimulus also facilitates or impairs the person's subjective experience of the stimulus. As Strack, Martin, and Stepper (1988) showed by varying the way in which participants held a pen in their mouths, a cartoon is perceived as funnier when the viewer's face can respond with a smile than when pursed lips impair a smile, highlighting that facial muscle feedback plays a crucial role in subjective experience and judgment. In recent years, many consumers voluntarily exposed themselves to a treatment that impairs facial muscle response, namely botox injections. The unanticipated side-effects range from impaired affective experience (Davis, Senghas, Brandt, \& Ochsner, 2010) to an impaired understanding of others' emotional expressions (Neil \& Chartrand, 2011) and impaired processing of emotion words (Havas, Glenberg, Gutowski, Lucarelli, \& Davidson, 2010). The latter findings show that understanding others' emotional expression, or merely comprehending emotionally charged words, involves activity of the facial muscles that are part of one's own emotional expression. This is consistent with the assumption that all mental processes involve sensory simulation (Barsalou, 1999) and draws attention to the role of the body in many basic psychological functions that are usually conceptualized in amodal ways.

As the body's role in basic psychological processes receives more attention, we will increasingly encounter evidence that familiar psychological phenomena have previously unknown bodily underpinnings. As an example, consider the mere exposure effect (Zajonc, 1968), that is, the observation that we like things more, the more often we are exposed to them. This is the case because repeated exposure facilitates easy processing, which is experienced as pleasant; accordingly, any other variable that increases processing fluency also increases 
liking (for reviews, see Reber, Schwarz, \& Winkielman, 2004; Schwarz, 2004). In an important series of studies, Topolinski and his colleagues identified the ease of motor processes as a crucial component of many fluency experiences. During reading, spontaneous subvocalization becomes easier with repetition - and impairing subvocalization by having perceivers chew gum eliminates the otherwise observed mere exposure effect, which is not the case for (equally distracting) motor tasks that do not impair subvocalization (Topolinski \& Strack, 2009). Similarly, exercises that facilitate the eye movements involved in a visual perception task enhance later liking of matching visual stimuli (Topolinski, 2010). Taking these observations to consumer behavior, Topolinski et al. (2014-in this issue) show that chewing popcorn in the cinema undermines the effectiveness of advertisements by interfering with subvocalization, thus reducing the fluency of motor processes that underlie language-based mere exposure effects.

Topolinski and colleagues' finding illustrates how a better understanding of the bodily underpinnings of familiar phenomena can identify novel limiting conditions, with important theoretical and applied implications (Topolinski, 2012). Looking ahead, we assume that future embodiment research will identify bodily contributions to many other well-established psychological phenomena. In some cases, this will require a thorough reconceptualization of the phenomenon itself; in other cases, it will deepen our understanding of its component processes by adding a bodily level of analysis.

Finally, just as cognition is impacted by the senses, sensory perception too may be affected by externally provided information. Elder and Krishna (2010) showed participants text advertisements for foods that either encompassed a single sense or multiple senses; then, they had the subjects taste the food. They found that taste perception was affected by the externally provided information so that the food tasted better when the information encompassed several senses. They explain their results as the advertisement impacting the sensory thoughts that subjects generate which subsequently affects taste perception. While the recent research focus has been on showing the effect of the senses on cognition, little research attention has been devoted to the effect of information on sensory perception. There is much scope for additional research exploring the effect of information on sensory perception.

\section{Sensory experience, mental simulation, and stimulus attributes}

People perceive the world through their senses. But the representations they construct from sensory inputs are not necessarily valid reflections of stimulus properties, a fact that gave rise to an enduring interest in illusions of sensory perception from early philosophy to current neuroscience. Much research in consumer behavior and psychology contributed to documenting such (visual) illusions (e.g., Krishna \& Raghubir, 1997; Raghubir \& Krishna, 1996, 1999; Wansink \& Van Ittersum, 2003; for a review see Krishna, 2007), showing how they may be impacted by individual traits such as self-construal (Krishna, Zhou, \&
Zhang, 2008) or ameliorated by the addition of another sensory input (Krishna, 2006).

Extending the work on sensory illusions, recent research has revisited the veridicality of perception from the perspective of goal directed action: If the purpose of cognition is to enable adaptive action, are action relevant aspects of sensory perception less likely to be distorted in maladaptive ways? Conversely, do our goals influence how we "see" the external world? If so, are the distortions adaptive? The answer is almost certainly a resounding, "It depends!" Nevertheless, the accumulating evidence supports a more favorable perspective on the role of distortions than most researchers would have assumed a decade ago.

For example, some findings suggest that visual illusions (e.g., illusions of size) exert more influence on choice and verbal reports (Which figure is larger?) than on bodily actions, such as the grip strength with which people try to grasp the figure (e.g., Aglioti, DeSouza, \& Goodale, 1995). However, the conditions under which this is the case, and how it is properly assessed, are subject of some controversy (Milner \& Dyde, 2003; Smeets \& Brenner, 2006). Other findings show that perception is highly sensitive to the perceiver's goals and bodily states and "informs people about opportunities for action and their associated costs" (Proffitt, 2006, p. 110). For example, hills seem steeper when we wear a heavy backpack (e.g., Proffitt, Bhalla, Gossweiler, \& Midgett, 1995), but their slope flattens when we bring some friends along for social support (e.g., Schnall, Harber, Stefanucci, \& Proffitt, 2008). Such findings reflect that perception stands in the service of action and takes the perceiver's resources into account. This "economy-of-action" approach to perception (Proffitt, 2006) sheds new light on classic issues of motivated biases that have preoccupied psychologists since the "New Look" of the 1950's (Bruner, 1957). Cornil, Ordabayeva, Kaiser, Weber, and Chandon (2014-in this issue) contribute to current analyses of goal sensitive perception by exploring the role of attitude ambivalence. On theoretical grounds one might expect that the ambivalence that results from mixed preferences fosters more detailed, and potentially more accurate, assessments. Compatible with this notion, Cornil and colleagues find that ambivalence in the form of desiring a food that one finds unhealthy can increase perceivers' visual sensitivity to portion size. From an applied perspective, this suggests that framing foods as vices may improve portion size perception among health conscious consumers.

Further highlighting the close link between perception and situated action, numerous studies show that merely perceiving an object elicits simulations of the actions it affords. For example, Tucker and Ellis (1998) showed that seeing the handle of a cup elicits a grasping simulation that is sufficient to interfere with motor performance on a concurrent task. Such spontaneous simulations can even be observed when people merely read a word (e.g., Tucker \& Ellis, 2001) - and exposure to "hammer" elicits a different type of grasp ("power" versus "precision") than exposure to "grape", reflecting the differential motor activity that would be appropriate in handling these objects. Elder and Krishna (2012) explored the implications of such embodied 
simulations for consumer behavior and advertising. They found higher purchase intentions when the visual orientation of objects in an advertisement facilitated mental simulation of interacting with the object; for example, a piece of cake seemed more appealing when the fork sitting next to it was oriented toward one's dominant (rather than nondominant) hand, thus facilitating mental simulation of grasping the fork to eat the cake. These beneficial effects of visual orientation were disrupted when participants' dominant hand held another object, which impaired the spontaneous consumption simulation. As in the work of Topolinski et al. (2014-in this issue), incongruent motor activity exerted a profound influence on consumers' preference formation. Such findings, and related evidence bearing on the role of motor simulations in the processing of action language (e.g., Pulvermüller, 2005) and related tasks, raise new questions about the conceptualization of processing fluency (Reber et al., 2004; Schwarz, in press) and call for a closer examination of the sensorimotor underpinnings of metacognitive experience.

We emphasize, however, that not all simulations will exert an influence through the same pathways. Whereas the effects reported by Elder and Krishna (2012) and Topolinski et al. (2014-in this issue) can be plausibly conceptualized as mental motor action affordance or even fluency effects (Reber et al., 2004), the role of mimicry and facial muscle responses in empathy and emotion processing (e.g., Havas et al., 2010; Neil \& Chartrand, 2011), for example, is more likely to reflect the role of interoceptive processes in emotion experience; similarly "engagement" through mental simulation can also drive preference as has been shown through dynamic imagery (mental simulation of movement for a static object; Cian, Krishna, \& Elder, 2014). Identifying different pathways of simulation effects, and their possible interactions, provides a promising avenue for future research.

Neuropsychological work also indicates that conceptual processing of food information is associated with increased activation of brain areas involved in the processing of tastes and rewards (e.g., Simmons, Martin, \& Barsalou, 2005). Indeed, the mental simulation of food consumption is sufficient to elicit satiation, as first shown with explicit simulation instructions (Morewedge, Huh, \& Vosgerau, 2010). Going beyond this observation, Larson, Redden, and Elder (2014-in this issue) find that satiation effects can emerge even when mental simulation is automatic rather than deliberate. This work complements research in sensory marketing that addresses how communications (Elder \& Krishna, 2012), other senses (e.g., haptics, Biswas, Szocs, Krishna, \& Lehmann, 2013; Krishna \& Morrin, 2008) and mental simulation (Eelen, Dewitte, \& Warlop, 2013; Elder \& Krishna, 2012; Shen \& Sengupta, 2012) impact taste perception and intention to purchase a food item.

Other sensory research in consumer psychology has produced a rich body of observations that bear on how sensory attributes of products, advertisements, and retail spaces influence consumers' thoughts, feelings, and decisions (for reviews, see Krishna, 2012, 2013, and the contributions in Krishna, 2010). Much of this work focused on vision. Extending this body of work, Meert, Pandelaere, and Patrick (2014-in this issue) find that adults as well as children prefer glossy objects over matte objects. They argue that this preference reflects an association of water and glossy surfaces, suggesting that it may be driven by the importance of water in the development of the species. Testing this conjecture, they find that thirst increases consumers' preference for glossiness even in domains unrelated to water, implicating current bodily states in preference formation. Exploring the association of brightness and temperature, $\mathrm{Xu}$ and Labroo (2014-in this issue) suggest that ambient brightness may affect perceptions of temperature and may trigger more intense emotional responses. Their findings are compatible with these conjectures. Also addressing brightness, Semin and Palma (2014-in this issue) note a consistent alignment of female gender with light colors and male gender with dark colors. Their experiments show that this alignment affects language processing as well as consumer preferences.

Other consumer research has addressed the haptic properties of consumer goods (Peck \& Childers, 2003) and communications (Peck \& Wiggins, 2006) and their impact on purchase intention, donation behaviors, and feelings of ownership and endowment (Peck \& Shu, 2009; Shu \& Peck, 2011). Adding to this stream of research, Brasel and Gips (2014-in this issue) focus on the touch-aspects of computer interfaces. Their findings suggest that the physical interaction with touch screens enhances consumers' sense of psychological ownership and endowment. Complementing their discussion of embodied influences on endowment effects, Florack, Kleber, Busch, and Stöhr (2014-in this issue) note that consumers' sense of ownership can be reduced through physical cleansing. As becomes apparent from these examples, many perceptual attributes are likely to exert (some of) their influence through metaphorical associations. We return to this issue in the next section, which also addresses additional aspects of haptic experience, such as temperature and warmth.

Consumer psychologists studying smell have explored ambient (Mitchell, Kahn, \& Knasko, 1995; Morrin \& Ratneshwar, 2003) as well as product smell (Krishna, Lwin, \& Morrin, 2010; Lwin, Morrin, \& Krishna, 2010; Morrin, Krishna, \& Lwin, 2011). Much of this work has either focused on the effect of ambient smell on in-store behavior (e.g., Mitchell et al., 1995; Spangenberg, Crowley, \& Henderson, 1996) or on showing the strong connection between smell and memory (for reviews of what is currently known about olfaction and the role of scent in marketing see Herz, 2010; Morrin, 2010). For instance, Krishna et al. (2010) show that a distinctly scented object enhances recall for other attributes of the object; this happens both with and without a scent-aid being present at the time of recall, indicating that this is not another form of encoding specificity; furthermore, the memory enhancement effect of scent is larger in the long-term as memory erodes faster in the unscented condition.

Despite the research discussed above, experimental research into smell and audition has remained fairly elusive in consumer psychology, even though scents and sounds are extensively used in marketing (for a review of the role of sounds in the marketplace see Meyers-Levy, Bublitz, \& Peracchio, 2009). One reason for the smaller amount of work on these senses may be the difficulty in controlling olfactory and auditory input, as compared to haptic and taste input. Changing the roughness, hardness, weight or temperature of an object, while keeping 
other haptic aspects constant, is relatively easy. Similarly, changing sweetness or saltiness or foods is straightforward. However, having the same intensity of smell input across participants is a complex and time consuming task; similarly, varying one dimension of sound (e.g., pitch) while controlling for the others poses nontrivial challenges. Hence, the exploration of smell is often restricted to manipulations that require only limited variation of smell intensity or that ask participants to imagine a smell, a task that can affect salivation and desire for food (e.g., Krishna, Morrin, \& Sayin, in press).

\section{Metaphors}

For many consumer researchers, embodied cognition is probably synonymous with one particular stream of research, namely work that illuminates how sensory experience in one domain can influence cognition, emotion, and behavior in a different domain in ways that follow familiar metaphors. Depending on theoretical perspective, metaphors are either seen as the unique driver of the observed effects (Lakoff, 2008; Lakoff \& Johnson, 1999) or as expressions of the multimodal nature of mental representations (Anderson, 2010; Barsalou, 2008; Williams et al., 2009). The current interest in metaphors breaks with a long tradition in philosophy and linguistics that treated metaphors as rhetorical devices best reserved for poets (for a review, see Ortony, 1993). While the underlying processes are subject to some debate (see the contributions in Landau, Robinson, \& Meier, 2014), the accumulating evidence makes a compelling case that a metaphor-consistent grounding of abstract thought in sensory experience can result in pervasive effects of bodily states on targets that are merely metaphorically related (for reviews, see Landau et al., 2010, 2014; Lee \& Schwarz, 2014).

One metaphorical link that figures prominently in the present special issue is the association of physical and social warmth, which is abundantly reflected in everyday language (e.g., when we talk about a "warm" person, who is unlikely to be shown a "cold shoulder"). Initial explorations of this metaphor found, for example, that people perceive others as socially warmer after they hold a warm rather than cold cup of coffee (Williams \& Bargh, 2008; see also Ijzerman \& Semin, 2009) and experience a room as physically colder after having been socially rejected (Zhong \& Leonardelli, 2008; see also Izjerman \& Semin, 2010). Taking these observations to the consumer domain, Lee, Rotman, and Perkins (2014, this volume) report that consumers perceived the ambient temperature to be cooler when eating alone than when eating with a partner; conversely, cool temperatures increased the desire for social consumption settings. Their findings highlight the bidirectional relationship between physical and social warmth (Bargh \& Shalev, 2012) and converge with Hong and Sun's (2012) observation that cool temperatures increase consumers' preference for romance movies. As Lee and colleagues note, these findings suggest promising avenues for research into the role of consumption contexts in the self-regulation of social closeness and loneliness.
Noting that feelings of social closeness are likely to foster conformity, Huang, Zhang, Hui, and Wyer (2014, this volume) test whether ambient temperature influences conformity in judgment and decision making. In laboratory and field studies they observe higher conformity under warm than cool temperature conditions. Their analysis of underlying process suggests that the opinions of close others exert more influence because they are perceived as more valid - even when the perception of social closeness merely results from a warm room.

Zwebner, Lee, and Goldenberg (2014-in this issue) ask whether the association of physical and socio-emotional warmth also extends to products. They find that warm ambient temperatures are associated with more positive affective responses and lower perceived distance to the target product, resulting in increased product valuation. This "temperature-premium effect" is robust across several laboratory and field studies and future research may fruitfully address the relative contributions of different affective and metaphorical pathways.

Other contributions to this special issue address sensory variables that have previously received little attention. $\mathrm{Xu}$ and Labroo (2014, this volume) suggest that ambient brightness is associated with ambient heat and may foster more extreme affective responses through that association. Their findings are consistent with this prediction across a variety of measures, including consumers' perceptions of aggressiveness and sexiness as well as food preferences. Shalev (2014-in this issue) draws attention to biological links between water supply and energy, which are also reflected in metaphors. She finds that exposure to dryness cues not only increases perceivers' experience of thirst, but also decreases their own as well as others' perceived level of energy and vitality. More important, perceptions of lower energy, induced through actual thirst or exposure to images of arid land, influenced participants' performance on problem solving tasks.

Whereas the metaphorical link of physical warmth is primarily to social warmth, other physical dimensions have many different metaphorical associations. A key example is verticality, which is associated with valence (good things are up; e.g., Meier \& Robinson, 2004), power (e.g., Schubert, 2005), godliness (e.g., Meier, Hauser, Robinson, Friesen, \& Schjeldahl, 2007), rationality, and other dimensions of judgment. Which of these diverse meanings of verticality is recruited at a given point in time is likely to depend on its relative accessibility and applicability to the task at hand, consistent with general principles of the context-sensitive construal of meaning (for a general review, see Schwarz, 2010). Ostinelli, Luna, and Ringberg (2014-in this issue) draw on the association of verticality and valence. Consistent with earlier research, they observe that imagining upward movement has positive evaluative consequences, in their case by boosting feelings of self-worth. Yet high self-worth is not always a beneficial thing (for a review, see Baumeister, Campbell, Krueger, \& Vohns, 2003) - while upward movement makes people feel better about themselves, it undermines their motivation for further improvement and hurts their actual task performance. These findings add to the literatures on mental simulation and metaphors as well as self-esteem. Complementing these findings, other work 
has shown that washing one's hands after failure eliminates the otherwise observed negative influence of failure on people's self-perceptions but hurts their performance on subsequent tasks by undermining their motivation to exert the required effort (Kaspar, 2013).

Interest in the psychological consequences of physical cleansing was stimulated by an important series of studies by Zhong and Liljenquist (2006), who explored the metaphorical link between physical and moral purity. These links are apparent in language use, from the Psalms' (24:4) notion of "clean hands and a pure heart" to everyday references to "dirty hands" or a "dirty mouth" (Lee \& Schwarz, 2010a). Testing the behavioral consequences of the physical-moral purity link, Zhong and Liljenquist (2006) found that immoral thoughts increased the appeal of cleaning products and using those products to clean one's hands eliminated the impact of guilt on subsequent behavior. Later work found that the power of physical cleansings is not limited to "dirty" thoughts and behaviors; instead, physical cleansings seem to metaphorically remove diverse traces of the past, from the cognitive dissonance resulting from difficult choices (Lee \& Schwarz, 2010b) to the impact of previous good or bad luck on risk taking (Xu, Zwick, \& Schwarz, 2012) and the influence of failure on subsequent performance (Kaspar, 2013). Such diverse effects, unrelated to moral purity, suggest that physical cleansing can metaphorically remove diverse traces of the past, essentially allowing people to "wipe the slate clean" (for a review, see Lee \& Schwarz, 2011). Extending the observation of clean-slate effects to another classic phenomenon of consumer research, Florack et al. (2014-in this issue) report that washing one's hands is also sufficient to attenuate the otherwise robust endowment effect. In their studies, consumers who were endowed with a product were more likely to exchange it for another one after they had cleansed their hands; importantly, this effect was only observed when participants engaged in an actual physical cleansing, not when they were merely exposed to cleaning primes.

In the final contribution to this special issue, Marin, Reimann, and Castaño (in this issue) show how exposure to images that carry metaphoric meaning can enhance or impair perceivers' creativity. Going beyond the demonstration of novel metaphor effects, they also find that the influence of visual metaphors on creative performance is moderated by perceivers' analogical reasoning skills and requires creative intent.

Whereas consumer psychologists have provided compelling illustrations of the impact of metaphors on consumer behavior, they have mostly remained silent on the broader conceptual debate in psychology and linguistics that centers on the extent to which metaphors are "merely" linguistic, embodied, or both (see, e.g., Barsalou, Santos, Simmons, \& Wilson, 2008; Landau et al., 2010). This issue is notoriously difficult to settle and the available evidence indicates that metaphors can exert their influence through multiple pathways, consistent with the assumption that mental representations are multimodal. Hence, it is not surprising that metaphor effects can be observed in response to sensory experiences as well as semantic primes and neither pathway precludes the other.

\section{Concluding remarks}

In combination, the contributions to this special issue illustrate the richness of current research at the interface of sensory marketing, grounded cognition, embodiment, and consumer behavior. Most of the reported findings are difficult to reconcile with standard models of judgment and decision making and reinforce the need to reconsider human cognition as grounded in the sensory experience resulting from goal directed interaction with the world. At the same time, the challenge to the dominant paradigm is more compelling than the identification of alternatives and more detailed conjectures about alternative mechanisms, along with focused tests of their relative merits, would be welcome. We emphasize, however, that testing the breadth and ubiquity of embodiment effects is itself a valuable contribution to the body of phenomena that need accounting. We were surprised by the extent to which some reviewers discounted any challenge to standard models of information processing as long as the model is not replaced with a fully worked out alternative. As André Gide (1925/1973) put it, one cannot discover new lands without consenting to lose sight of the shore for a while and tolerance for (partial) ambiguity is a prerequisite for creative exploration. Equally surprising was that many of the more than 70 submissions we received made little attempt to address the larger conceptual issues or to even identify the challenge their findings present. Hopefully, both surprises will become less common as work in this important area progresses.

\section{References}

Aglioti, S., DeSouza, J. F. X., \& Goodale, M. A. (1995). Size-contrast illusions deceive the eye but not the hand. Current Biology, 5, 679-685.

Anderson, M. L. (2008). On the grounds of x-grounded cognition. In P. Calvo, \& T. Gomila (Eds.), The Elsevier handbook of cognitive science: An embodied approach (pp. 423-435). Amsterdam: Elsevier.

Anderson, M. (2010). Neural reuse: A fundamental organizational principle of the brain. Behavioral and Brain Sciences, 33, 245-266.

Bargh, J. A., \& Shalev, I. (2012). The substitutability of physical and social warmth in daily life. Emotion, 12, 154-162.

Barsalou, L. W. (1999). Perceptual symbol systems. Behavioral and Brain Sciences, 22, 577-660.

Barsalou, L. W. (2008). Grounded cognition. Annual Review of Psychology, 59(1), 617-645.

Barsalou, L. W., Niedenthal, P. M., Barbey, A., \& Ruppert, J. (2003). Social embodiment. The Psychology of Learning and Motivation, 43, 43-92.

Barsalou, L. W., Santos, A., Simmons, K., \& Wilson, C. D. (2008). Language and simulation in conceptual processing. In M. De Vega, A. M. Glenberg, \& A. C. Graesser (Eds.), Symbols, embodiment, and meaning (pp. 245-283). New York: Oxford University Press.

Baumeister, R. F., Campbell, J. D., Krueger, J. I., \& Vohns, K. D. (2003). Does high self-esteem cause better performance, interpersonal success, happiness, or healthier lifestyles? Psychological Science in the Public Interest, 4, 1-44.

Biswas, D., Szocs, C., Krishna, A., \& Lehmann, D. (2013). Something to chew on: Effect of food-haptics on mastication and calorie estimation. conditionally accepted at. Journal of Consumer Research.

Bower, G. H. (1981). Mood and memory. American Psychologist, 36, $129-148$

Brasel, S. A., \& Gips, J. (2014). Tablets, touchscreens, and touchpads: How varying touch interfaces trigger psychological ownership and endowment. Journal of Consumer Psychology, 24(2), 226-233 (in this issue). 
Bruner, J. S. (1957). On perceptual readiness. Psychological Review, 64, 123-152. Cian, L., Krishna, A., \& Elder, R. (2014). The evoked-dynamism effect: Dynamic imagery from static brand logos. Journal of Marketing Research.

Cornil, Y., Ordabayeva, N., Kaiser, U., Weber, B., \& Chandon, P. (2014). The acuity of vice: Attitude ambivalence improves visual sensitivity to increasing portion sizes. Journal of Consumer Psychology, 24(2), 177-187 (in this issue).

Davis, J. I., Senghas, A., Brandt, F., \& Ochsner, K. N. (2010). The effects of botox injections on emotional experience. Emotion, 10, 433-440.

Eelen, J., Dewitte, S., \& Warlop, L. (2013). Situated embodied cognition: Monitoring orientation cues affects product evaluation and choice. Journal of Consumer Psychology, 23(4), 424-433.

Elder, R., \& Krishna, A. (2010). The effect of advertising copy on sensory thoughts and perceived taste. Journal of Consumer Research, 36(5), 748-756.

Elder, R., \& Krishna, A. (2012). The visual depiction effect: Inducing embodied mental simulation that evokes motor responses. Journal of Consumer Research, 38(6), 988-1003.

Florack, A., Kleber, J., Busch, R., \& Stöhr, D. (2014). Detaching the ties of ownership: The effects of hand washing on the exchange of endowed products. Journal of Consumer Psychology, 24(2), 284-289 (in this issue).

Gide, A. (1925/1973). Les faux-monnayeurs. Paris: Editions Flammarion.

Havas, D. A., Glenberg, A. M., Gutowski, K. A., Lucarelli, M. J., \& Davidson, R. J. (2010). Cosmetic use of botulinum toxin-A affects processing of emotional language. Psychological Science, 21, 895-900.

Herbert, B., \& Pollatos, O. (2012). The body in the mind. On the relationship between interoception and embodiment. Topics in Cognitive Science, 4(4), $692-704$.

Herz, R. (2010). The emotional, cognitive and biological basics of olfaction: Implications and considerations for scent marketing. In A. Krishna (Ed.), Sensory marketing: Research on the sensuality of products (pp. 75-86). New York: Routledge, Psychology Press.

Hong, J., \& Sun, Y. (2012). Warm it up with love: The effect of physical coldness on liking of romance movies. Journal of Consumer Research, 39(2), 293-306.

Huang, X. I., Zhang, M., Hui, M. K., \& Wyer, R. S. (2014). Warmth and conformity: The effects of ambient temperature on product preferences and financial decisions. Journal of Consumer Psychology, 24(2), 241-250.

Ijzerman, H., \& Semin, G. R. (2009). The thermometer of social relations. Psychological Science, 20, 1214-1220.

Izjerman, H., \& Semin, G. (2010). Temperature perceptions as a ground for social proximity. Journal of Experimental Social Psychology, 46, 867-873.

James, W. (1890). Principles of psychology, Vols. 1-2, . New York: Dover.

Kaspar, K. (2013). Washing one's hands after failure enhances optimism but hampers future performance. Social Psychological and Personality Science, 4(1), 69-73.

Kosslyn, S. M., Thompson, W. L., \& Ganis, G. (2006). The case for mental imagery. New York: Oxford University Press.

Krishna, A. (2006). The interaction of senses: The Effect of vision and touch on the elongation bias. Journal of Consumer Research, 32(4), 557-566.

Krishna, A. (2007). Biases in spatial perception: A review and integrative framework. In M. Wedel, \& R. Pieters (Eds.), Visual marketing: From attention to action. Mahwah, New Jersey: Lawrence Erlbaum Associates.

Krishna, A. (2010). Sensory marketing: Research on the sensuality of products. New York: Routledge.

Krishna, A. (2012). An integrative review of sensory marketing: Engaging the senses to affect perception, judgment and behavior. Journal of Consumer Psychology, 22(3), 332-351.

Krishna, A. (2013). Customer sense: How the 5 senses influence buying behavior. New York: Palgrave Macmillan.

Krishna, A., Lwin, M. O., \& Morrin, M. (2010). Product scent and memory. Journal of Consumer Research, 37(1), 57-67.

Krishna, A., \& Morrin, M. (2008). Does touch affect taste? The perceptual transfer of product container haptic cues. Journal of Consumer Research, 34, 807-818.

Krishna, A., Morrin, M., \& Sayin, E. (2013). Drooling over the imagined smell of cookies: A focus on olfactory imagery. Journal of Consumer Research (in press).

Krishna, A., \& Raghubir, P. (1997). The effect of line configuration on perceived numerosity of dotted lines. Memory and Cognition, 25(4), 492-507.
Krishna, A., Zhou, R., \& Zhang, S. (2008). The effect of self-construal on spatial judgments. Journal of Consumer Research, 35(2), 337-348.

Lachman, R., Lachman, J. T., \& Butterfield, E. C. (1979). Cognitive psychology and information processing. Hillsdale, NJ: Erlbaum.

Lakoff, G. (2008). The neural theory of metaphor. In W. W. Gibbs (Ed.), The Cambridge handbook of metaphor and thought (pp. 17-38). New York: Cambridge University Press.

Lakoff, G., \& Johnson, M. (1999). Philosophy in the flesh: The embodied mind and its challenges to western thought. New York: Basic Books.

Landau, M. J., Meier, B. P., \& Keefer, L. A. (2010). A metaphor-enriched social cognition. Psychological Bulletin, 136, 1045-1067.

Landau, M. J., Robinson, M. D., \& Meier, B. P. (Eds.). (2014). The power of metaphor: Examining its influence on social life. Washington, DC: APA.

Larson, J. S., Redden, J. P., \& Elder, R. S. (2014). Satiation from sensory simulation: Evaluating foods decreases enjoyment of similar foods. Journal of Consumer Psychology, 24(2), 188-194 (in this issue).

Lee, S. H. M., Rotman, J. D., \& Perkins, A. W. (2014). Embodied cognition and social consumption: Self-regulating temperature through social products and behaviors. Journal of Consumer Psychology, 24(2), 234-240.

Lee, S. W. S., \& Schwarz, N. (2010). Of dirty hands and dirty mouths: Embodiment of the moral purity metaphor is specific to the motor modality involved in moral transgression. Psychological Science, 21, 1423-1425.

Lee, W. S., \& Schwarz, N. (2010). Washing away post-decisional dissonance. Science, 328, 709

Lee, S. W. S., \& Schwarz, N. (2011). Clean slate effects: The psychological consequences of physical cleansing. Current Directions in Psychological Science, 20, 307-311.

Lee, S. W. S., \& Schwarz, N. (2014). Metaphors in judgment and decision making. In M. J. Landau, M. D. Robinson, \& B. P. Meier (Eds.), The power of metaphor: Examining its influence on social life (pp. 85-108). Washington, DC: APA.

Lichtenstein, S., \& Slovic, P. (Eds.). (2006). The construction of preference. New York: Cambridge University Press.

Lwin, M., Morrin, M., \& Krishna, A. (2010). Exploring the superadditive effects of scent and pictures on verbal recall: An extension of dual coding theory. Journal of Consumer Psychology, 20(3), 317-326.

Marin, A., Reimann, M., \& Castaño, R. (2014). Metaphors and creativity: Direct, moderating, and mediating effects. Journal of Consumer Psychology, 24(2), 290-297 (in this issue).

Meert, K., Pandelaere, M., \& Patrick, V. M. (2014). Taking a shine to it: How the preference for glossy stems from an innate need for water. Journal of Consumer Psychology, 24(2), 195-206 (in this issue).

Meier, B. P., Hauser, D. J., Robinson, M. D., Friesen, C. K., \& Schjeldahl, K. (2007). What's "up" with God? Vertical space as a representation of the divine. Journal of Personality and Social Psychology, 93, 699-710.

Meier, B. P., \& Robinson, M. D. (2004). Why the sunny side is up: Associations between affect and vertical position. Psychological Science, 15, 243-247.

Meier, B. P., Schnall, S., Schwarz, N., \& Bargh, J. (2012). Embodiment in social psychology. Topics in Cognitive Science, 4, 705-716.

Meyers-Levy, J., Bublitz, M. G., \& Peracchio, L. A. (2009). The sounds of the marketplace: The role of audition in marketing. In A. Krishna (Ed.), Sensory marketing: Psychological research for consumers (pp. 137-157). Hove, UK: Psychology Press.

Milner, D., \& Dyde, R. (2003). Why do some perceptual illusions affect visually guided action, when others don't? Trends in Cognitive Sciences, 7, 10-11.

Mitchell, D. J., Kahn, B. E., \& Knasko, S. C. (1995). There's something in the air: Effects of congruent or incongruent ambient odor on consumer decision making. Journal of Consumer Research, 22, 229-238.

Morewedge, C. K., Huh, Y. E., \& Vosgerau, J. (2010). Thought for food: Imagined consumption reduces actual consumption. Science, 330(6010), 1530-1533.

Morrin, M. (2010). Scent marketing: An overview. In A. Krishna (Ed.), Sensory marketing: Research on the sensuality of products (pp. 75-86). New York: Routledge, Psychology Press.

Morrin, M., Krishna, A., \& Lwin, M. (2011). Retroactive interference from scent cues and the effect on product recall. Journal of Consumer Psychology, 21(3), 354-361.

Morrin, M., \& Ratneshwar, S. (2003). Does it make sense to use scents to enhance brand memory? Journal of Marketing Research, 40, 10-25. 
Neil, D. T., \& Chartrand, T. L. (2011). Embodied emotion perception: Amplifying and dampening facial feedback modulates emotion perception accuracy. Social Psychological and Personality Science, 2, 673-678.

Niedenthal, P. M., Barsalou, L. W., Winkielman, P., Krauth-Gruber, S., \& Ric, F. (2005). Embodiment in attitudes, social perception, and emotion. Personality and Social Psychology Review, 9, 184-211.

Ortony, A. (1993). Metaphor, language, and thought. In A. Ortony (Ed.), Metaphor and thought (pp. 1-18). New York: Cambridge University Press.

Ostinelli, M., Luna, D., \& Ringberg, T. (2014). When up brings you down: The effects of imagined vertical movements on motivation, performance, and consumer behavior. Journal of Consumer Psychology, 24(2), 271-283 (in this issue)

Paivio, A. (1971). Imagery and verbal processes. New York: Holt, Rinehart \& Winston

Peck, J., \& Childers, T. L. (2003). To have and to hold: The influence of haptic information on product judgments. Journal of Marketing, 67, 35-48.

Peck, J., \& Shu, S. (2009). The effect of mere touch on perceived ownership. Journal of Consumer Research, 36(3), 434-447.

Peck, J., \& Wiggins, J. (2006). It just feels good: Customers' affective response to touch and its Influence on persuasion. Journal of Marketing, 70(4), 56-69.

Proffitt, D. R. (2006). Embodied perception and the economy of action. Perspectives on Psychological Science, 1, 110-122.

Proffitt, D. R., Bhalla, M., Gossweiler, R., \& Midgett, J. (1995). Perceiving geographical slant. Psychonomic Bulletin \& Review, 2, 409-428.

Pulvermüller, F. (2005). Brain mechanisms linking language and action. Nature Review Neuroscience, 6, 576-582.

Pylyshyn, Z. W. (1973). What the mind's eye tells the mind's brain: A critique of mental imagery. Psychological Bulletin, 80, 1-24.

Raghubir, P., \& Krishna, A. (1996). As the crow flies: Bias in consumers' map-based distance judgments. Journal of Consumer Research, 23, 26-39.

Raghubir, P., \& Krishna, A. (1999). Vital dimensions: Antecedents and consequences of biases in volume perceptions. Journal of Marketing Research, 36(3), 313-326.

Reber, R., Schwarz, N., \& Winkielman, P. (2004). Processing fluency and aesthetic pleasure: Is beauty in the perceiver's processing experience? Personality and Social Psychology Review, 8, 364-382.

Root-Bernstein, R. S. (1989). Discovering. Inventing and solving problems at the frontiers of scientific knowledge. Cambridge, MA: Harvard University Press.

Schnall, S., Harber, K. D., Stefanucci, J. K., \& Proffitt, D. R. (2008). Social support and the perception of geographical slant. Journal of Experimental Social Psychology, 44, 1246-1255.

Schubert, T. W. (2005). Your highness: Vertical positions as perceptual symbols of power. Journal of Personality and Social Psychology, 89, 1-21.

Schwarz, N. (1990). Feelings as information: Informational and motivational functions of affective states. In E. T. Higgins, \& R. M. Sorrentino (Eds.), Handbook of motivation and cognition. Foundations of social behavior, Vol. 2. (pp. 527-561). New York, NY: Guilford Press.

Schwarz, N. (2000). Agenda 2000: Attitudes and social judgment - Warmer, more social, and less conscious. European Journal of Social Psychology, $30,149-176$.

Schwarz, N. (2004). Meta-cognitive experiences in consumer judgment and decision making. Journal of Consumer Psychology, 14, 332-348.

Schwarz, N. (2007). Attitude construction: Evaluation in context. Social Cognition, 25, 638-656.

Schwarz, N. (2010). Meaning in context: Metacognitive experiences. In B. Mesquita, L. F. Barrett, \& E. R. Smith (Eds.), The mind in context (pp. 105-125). New York: Guilford.

Schwarz, N. (2012). Feelings-as-information theory. In P. A. M. Van Lange, A. Kruglanski, \& E. T. Higgins (Eds.), Handbook of theories of social psychology (pp. 289-308). Thousand Oaks, CA: Sage.

Schwarz, N. (2013). Metacognition. In E. Borgida, \& J. A. Bargh (Eds.), APA handbook of personality and social psychology. Attitudes and social cognition, Vol. 1, . Washington, DC: APA (in press).

Schwarz, N., \& Clore, G. L. (2007). Feelings and phenomenal experiences. In A. Kruglanski, \& E. T. Higgins (Eds.), Social psychology. Handbook of basic principles (pp. 385-407) (2nd ed.). New York: Guilford.

Schwarz, N., Servay, W., \& Kumpf, M. (1985). Attribution of arousal as a mediator of the effectiveness of fear-arousing communications. Journal of Applied Social Psychology, 15, 74-84.

Semin, R. G., \& Palma, T. A. (2014). Why the bride wears white Grounding gender with brightness. Journal of Consumer Psychology, 24(2), 217-225 (in this issue).

Shalev, I. (2014). Implicit energy loss: Embodied dryness cues influence vitality and depletion. Journal of Consumer Psychology, 24(2), 260-270 (in this issue).

Shen, H., \& Sengupta, J. (2012). If you can't grab it, it won't grab you: The effect of restricting the dominant hand on target evaluations. Journal of Experimental Social Psychology, 48, 525-529.

Shu, S., \& Peck, J. (2011). Psychological ownership and affective reaction: Emotional attachment process variables and the endowment effect. Journal of Consumer Psychology, 21(4), 439-452.

Simmons, W. K., Martin, A., \& Barsalou, L. W. (2005). Pictures of appetizing foods activate gustatory cortices for taste and reward. Cerebral Cortex, 15, $1602-1608$

Smeets, J. B. J., \& Brenner, E. (2006). 10 years of illusions. Journal of Experimental Psychology: Human Perception and Performance, 32, 1501-1504.

Smith, E. R., \& Semin, G. R. (2004). Socially situated cognition: Cognition in its social context. Advances in Experimental Social Psychology, 36, 53-117.

Spangenberg, E. R., Crowley, A. E., \& Henderson, P. W. (1996). Improving the store environment: Do olfactory cues affect evaluations and behavior? Journal of Marketing, 60, 67-80.

Strack, F., \& Deutsch, R. (2007). The role of impulse in social behavior. In A Kruglanski, \& E. T. Higgins (Eds.), Social psychology. Handbook of basic principles (pp. 408-431) (2nd ed.). New York: Guilford.

Strack, F., Martin, L. L., \& Stepper, S. (1988). Inhibiting and facilitating conditions of the human smile: A nonobtrusive test of the facial feedback hypothesis. Journal of Personality and Social Psychology, 54, 768-777.

Topolinski, S. (2010). Moving the eye of the beholder: Motor components in vision determine aesthetic preference. Psychological Science, 21, $1220-1224$

Topolinski, S. (2012). The sensorimotor contributions to implicit memory, familiarity, and recollection. Journal of Experimental Psychology: General, 141(2), 260-281.

Topolinski, S., Lindner, S., \& Freudenberg, A. -L. (2013). Popcorn in the cinema: Oral interference sabotages advertising effects. Journal of Consumer Psychology, 24(2), 169-176 (in this issue).

Topolinski, S., \& Strack, F. (2009). Motormouth: Mere exposure depends on stimulus specific motor simulations. Journal of Experimental Psychology: Learning, Memory, and Cognition, 35, 423-433.

Tucker, M., \& Ellis, R. (1998). On the relations between seen objects and components of potential actions. Journal of Experimental Psychology: Human Perception and Performance, 24(6), 830-846.

Tucker, M., \& Ellis, R. (2001). The potentiation of grasp types during visual object categorization. Visual Cognition, 8(6), 769-800.

Wansink, B., \& Van Ittersum, K. (2003). Bottoms up! The influence of elongation on pouring and consumption volume. Journal of Consumer Research, 30(3), 455-463.

Williams, L. E., \& Bargh, J. A. (2008). Experiencing physical warmth influences interpersonal warmth. Science, 322, 606-607.

Williams, L. E., Huang, J. Y., \& Bargh, J. A. (2009). The scaffolded mind: Higher mental processes are grounded in early experience of the physical world. European Journal of Social Psychology, 39, $1257-1267$.

Wilson, M. (2002). Six views of embodied cognition. Psychonomic Bulletin and Review, 9, 625-636.

Wyer, R. S. (1974). Cognitive organization and change: An information processing approach. Hillsdale, NJ: Erlbaum.

Xu, A. J., \& Labroo, A. (2014). Incandescent affect: Turning on the hot emotional system with bright light. Journal of Consumer Psychology, 24(2), $207-216$ (in this issue). 
Xu, A. J., Zwick, R., \& Schwarz, N. (2012). Washing away your (good or bad) luck: Physical cleansing affects risk-taking behavior. Journal of Experimental Psychology: General, 141, 26-30.

Zajonc, R. B. (1968). Attitudinal effects of mere exposure. Journal of Personality and Social Psychology Monograph, 9(2), 1-27.

Zhong, C. B., \& Leonardelli, G. J. (2008). Cold and lonely: Does social exclusion feel literally cold? Psychological Science, 19, 838-842.

Zhong, C. B., \& Liljenquist, K. (2006). Washing away your sins: Threatened morality and physical cleansing. Science, 313, 1451-1452.
Zillman, D. (1978). Attribution and misattribution of excitatory reactions. In J. H. Harvey, W. I. Ickes, \& R. F. Kidd (Eds.), New directions in attribution research, Vol. 2. (pp. 335-368). Hillsdale, NJ: Erlbaum.

Zwebner, Y., Lee, L., \& Goldenberg, J. (2014). The temperature premium: Warm temperatures increase product valuation. Journal of Consumer Psychology, 24(2), 251-259 (in this issue). 